\title{
Adesão da equipe de enfermagem à higienização das mãos na unidade de terapia intensiva neonatal
}

\author{
Compliance with hand washing in a Neonatal Intensive Care Unit
}

Cumplimiento del lavado de manos en una unidad de cuidados intensivos neonatales

Hercules Pereira Coelho ${ }^{{ }^{*}}$, Isabelly Rayane Alves dos Santos ${ }^{1}$, Camila Maria do Nascimento ${ }^{1}$, Ana Beatriz Linard de Carvalho ${ }^{1}$, Cicera Emanuele do Monte Simão ${ }^{1}$, Ozeias Pereira de Oliveira², Carlos Vinicius Moreira Lima ${ }^{3}$, Luzianne Clemente de Meneses ${ }^{4}$, João Marcos Ferreira de Lima Silva ${ }^{1}$, Ana Maria Machado Borges ${ }^{1}$.

\section{RESUMO}

Objetivo: Avaliar a adesão dos profissionais de enfermagem à higienização das mãos na unidade de terapia intensiva neonatal. Métodos: Pesquisa observacional não participante, transversal, com abordagem quantitativa, realizada em três Unidades de Terapia Intensiva Neonatal. Os dados foram coletados mediante o uso do Formulário de Observação e Cálculo do Manual de Referência Técnica para a Higiene das Mãos do Ministério da Saúde. Resultados: A pesquisa contou com 2.006 oportunidades de higienização, a partir das quais foi evidenciada uma adesão de $77,2 \%$. Para os enfermeiros e técnicos de enfermagem foi predominante o uso do sabonete, $79 \%$, e $73,3 \%$, seguido do ato de não higienização das mãos, $14,3 \%$, e $19,6 \%$, respectivamente. Diante da adesão aos cinco momentos de higienização das mãos, observou-se índice expressivo na recomendação Antes de Tocar o Paciente, 95,2\% pelos enfermeiros. Para os técnicos de enfermagem, evidenciou-se maior adesão na indicação Após Risco de Exposição a Fluídos Corporais, 84,6\%. Para ambos os profissionais a menor adesão foi observada na indicação Após Tocar Superfícies Próximas ao Paciente. Conclusão: Diante dos resultados do estudo, verificou-se que a assistência ofertada pelos enfermeiros está classificada como segura, e a dos técnicos de enfermagem como limítrofe.

Palavras-chave: Higiene das mãos, Unidade de terapia intensiva neonatal, Segurança do paciente, Assistência de enfermagem.

\begin{abstract}
Objective: To evaluate the most adherent product used by nursing professionals for hand hygiene in the five moments recommended by the World Health Organization. Methods: A non-participant, cross-sectional observational research with quantitative approach, conducted in three Neonatal Intensive Care Units. Data were collected using the Observation and Calculation Form of the Ministry of Health Technical Reference Manual for Hand Hygiene. Results: The survey had 2,006 opportunities for hygiene, from which it was evidenced an adherence of $77.2 \%$. For nurses and nursing technicians, the use of soap was predominant,
\end{abstract}

1 Centro Universitário Doutor Leão Sampaio (UNILEÃO), Juazeiro do Norte - Ceará.

*E-mail: herculesleon_01@yahoo.com

2 Faculdades Integradas de Patos (FIP), Crato - Ceará.

${ }^{3}$ Faculdade de Juazeiro do Norte (FJN), Juazeiro do Norte - Ceará.

${ }^{4}$ Instituto de Medicina Integral Prof. Fernando Figueira (IMIP) - COREMU, Recife - Pernambuco.

Programa Institucional de Bolsa de Iniciação Científica e Tecnológica (PIBICT) do Centro Universitário Doutor Leão Sampaio (UNILEÃO). 
$79 \%$, and $73.3 \%$, followed by the not act of hand hygiene, $14.3 \%$, and $19.6 \%$, respectively. Given the adherence to the five moments of hand hygiene, there was a significant index in the recommendation Before Touching the Patient, $95.2 \%$ by nurses. For nursing technicians, there was greater adherence in the indication After Risk of Exposure to Body Fluids, 84.6\%. For both professionals, the lowest adherence was observed in the indication After Touching Nearly Surfaces. Conclusion: Given the results of the study, it was found that the care offered by nurses is classified as safe and that of nursing technicians as borderline.

Key words: Hand hygiene, Neonatal intensive care unit, Patient safety, Nursing care.

\section{RESUMEN}

Objetivo: Evaluar el producto más adherente utilizado por los profesionales de enfermería para la higiene de las manos en los cinco momentos recomendados por la Organización Mundial de la Salud. Métodos: Investigación observacional transversal no participativa con enfoque cuantitativo, realizada en tres unidades de cuidados intensivos neonatales. Los datos fueron recogidos utilizando el Formulario de observación y cálculo del Manual de referencia técnica de higiene de manos del Ministerio de Salud. Resultados: La investigación tuvo 2.006 oportunidades de higiene, de las cuales se evidenció una adherencia del 77,2\%. Para las enfermeras y los técnicos de enfermería, predominaba el uso de jabón, $79 \%$ y $73,3 \%$, seguido del acto de higiene de manos, $14,3 \%$ y $19,6 \%$, respectivamente. Dada la adhesión a los cinco momentos de higiene de manos, se observó índice expresivo en la recomendación Antes de Tocar al Paciente, 95.2\% por parte de las enfermeras. Para los técnicos de enfermería, hubo una mayor adherencia en la indicación Después del Riesgo de la exposición a los fluidos corporales, 84,6\%. Para ambos profesionales, la menor adherencia se observó en la indicación Después de Tocar las Superficies Cercanas al Paciente. Conclusión: Dados los resultados del estudio, se encontró que la atención ofrecida por las enfermeras se clasifica como segura, y la de los técnicos de enfermería como limítrofe.

Palabras clave: Higiene de manos, Unidad de cuidados intensivos neonatales, Seguridad del paciente, Atención de enfermería.

\section{INTRODUÇÃO}

Sob a ótica biológica, sabe-se que a pele é colonizada por diversos microrganismos, bactérias e fungos, os quais se apresentam de maneira distinta nas diversas áreas do corpo humano. Os microrganismos acentuam-se nas mãos dos profissionais da saúde, que, devido ao seu contato contínuo com materiais biológicos, podem apresentar concentração estimada de 104 a 106 unidades formadoras de colônias por centímetros quadrados ( $\left.\mathrm{cm}^{2}\right)$ (LLAPA-RODRíGUEZ EO, et al., 2018).

Neste contexto, para minimizar a carga microbiana e prevenir a transmissão cruzada de microrganismos, a Higienização das Mãos (HM) constitui-se como ação simples, rápida e de eficácia comprovada na prevenção das Infecções Relacionadas à Assistência em Saúde (IRAS), sendo esta considerada forte indicador da qualidade da assistência, frente à segurança do paciente (LLAPA-RODRÍGUEZ EO, et al., 2018; FELDHAUS C, et al., 2018).

Apesar da vasta disseminação de informações quanto à efetividade da HM como meio de prevenção das IRAS, a adesão dos profissionais a esta prática ainda é insuficiente, segundo dados da Organização Mundial da Saúde (OMS). Esta revela que 70\% dos profissionais da saúde não realizam a HM nos cinco momentos preconizados, a saber: Antes de Tocar o Paciente; Antes de Realizar Procedimento Limpo/Asséptico; Após o Risco de Exposição a Fluídos Corporais; Após Tocar o Paciente; e Após Tocar Superfícies Próximas ao Paciente (RAIMONDI DC, et al., 2017; BRASIL, 2013).

No ano de 2016, o Boletim de Segurança do Paciente e Qualidade em Serviços de Saúde no 16, evidenciou taxa de 4,6 a 13,6\% de densidade de incidência das IRAS por mil dispositivos/dias nas Unidades de Terapia Intensiva (UTI) do Brasil (BRASIL, 2017). 
Considerando as Unidades de Terapia Intensiva Neonatal (UTIN), a taxa de adesão dos profissionais da saúde à HM não é diferente. Fato este que, em detrimento da maior susceptibilidade do Recém-Nascido (RN), as IRAS podem comprometer a qualidade da assistência despendida aos neonatos, e, por conseguinte, acarretar danos a sua saúde e maiores despesas para as instituições hospitalares (PIMENTEL CS, et al., 2018).

Assim, levando em consideração que a HM é a principal precaução para prevenir e/ou controlar as infecções, é inerente a necessidade da adesão dos profissionais da saúde a esta prática, que pode ser realizada de duas formas distintas, são estas: higiene simples com água e sabonete líquido ou a fricção antisséptica com álcool 70\%, sendo esta última considerada padrão ouro pelo Ministério da Saúde (MS) (BRASIL, 2013; BRASIL, 2017).

Dada a importância da monitorização da taxa de adesão dos profissionais de enfermagem à HM, e sua respectiva ação frente aos cinco momentos preconizados pela OMS, tendo em vista a maximização da qualidade e a segurança da assistência despendida aos neonatos internados na UTIN, bem como, a redução do risco da ocorrência de infecções cruzadas entre a díade profissional-paciente, o estudo denota relevância (VASCONCELOS RO, et al., 2018).

Justifica-se a realização deste estudo pela necessidade de avaliar as ações dos profissionais de enfermagem frente à adesão à HM na UTIN, dada a maior incidência de infecções serem evidenciadas neste setor crítico das instituições de saúde. Também, é notória a baixa adesão dos profissionais de enfermagem a esta prática, que visa, prioritariamente, a segurança do paciente e dos próprios profissionais da saúde no seu contexto laboral.

Postula-se que o estudo contribuirá significativamente para o meio científico e social, tendo em vista a possibilidade de disseminar a ciência acerca da importância da adesão à HM como meio de promover a segurança do paciente nas instituições de saúde. Bem como, subsidiar medidas que favoreçam a adesão dos profissionais de enfermagem a tal técnica, com o intuito de qualificar a assistência em saúde. Espera-se ainda que auxilie na sustentabilidade do sistema de saúde e na redução de riscos adicionais aos usuários. Deste modo, o estudo tem como objetivo avaliar a adesão dos profissionais de enfermagem à higienização das mãos na unidade de terapia intensiva neonatal.

\section{MÉTODOS}

Trata-se de pesquisa observacional não participante, transversal, com abordagem quantitativa. $O$ estudo foi realizado em três UTIN (pública, filantrópica e privada) de referência para a atenção em neonatologia na região do Cariri Cearense, Brasil. Foi utilizado o Formulário de Observação e Cálculo do Manual de Referência Técnica para a Higiene das Mãos do Ministério da Saúde (BRASIL, 2009).

A população do estudo foi composta por todos os profissionais da equipe de enfermagem que atuavam nas supracitadas UTIN. Para a seleção foi empregado como critério de inclusão: profissionais da equipe de enfermagem das UTIN que estivessem atuando há no mínimo dois meses; e como critério de exclusão: os profissionais da equipe de enfermagem que desempenhassem apenas atividades gerenciais nas UTIN.

As observações ocorreram durante 15 dias, nos três turnos (manhã, tarde e noite) de trabalho dos participantes, com duração de uma hora de observação em cada período. A cada turno foi observada uma categoria profissional (enfermeiro ou técnico de enfermagem), de modo que eles não soubessem qual categoria estava sendo observada. A escolha ocorria da seguinte forma: ao adentrar nas UTIN, o observador aguardava surgir a primeira oportunidade assistencial ao neonato, e a partir daí, quando o profissional da equipe de enfermagem dava início a ação, a qual possuía indicação para HM, o observador assinalava no formulário de observação a categoria pertencente ao profissional, sendo essa a categoria escolhida para observação durante o turno. Não ocorreu observação simultânea de mais de um profissional.

Estudos observacionais são passíveis ao efeito Hawthorne, que consiste na mudança de comportamento e atitude dos participantes devido à presença do observador, modificando assim, os resultados dos estudos 
(ABRAHAM MB, et al., 2018). Mediante esse fenômeno, foram traçadas as seguintes estratégias na tentativa de minimizar esse efeito: os observadores se localizaram na bancada central da UTIN, considerado local estratégico para a observação dos profissionais; foram realizadas cinco observações-piloto, por observador, em cada um dos turnos, permitindo familiarizar-se com o ambiente e com o método empregado, além do participante da pesquisa acostumar-se com o observador. As observações-piloto não fizeram parte da amostra do estudo.

As ações a serem executadas pelos profissionais de enfermagem poderiam ser a fricção com álcool; a lavagem com água e sabão; lavagem das mãos com água e sabão e fricção alcoólica, de modo simultâneo; o uso da luva de procedimentos em substituição a HM; ou a não realização de ação de HM.

Os dados dessas observações foram assinalados em formulários impressos, sendo posteriormente digitados em planilha eletrônica no programa Microsoft Office Excel® (versão 2010), com dupla digitação independente, e, conseguinte, verificação de inconsistências de digitação. Os dados foram processados no programa Statistical Package for the Social Sciences (SPSS) (versão 21), e analisados por meio da estatística descritiva, com frequências absolutas ( $\mathrm{n}$ ) e relativas (\%).

Ressalta-se que a pesquisa obedeceu a todos os preceitos éticos e legais da Resolução $n^{\circ} 466 / 12$, do Conselho Nacional de Saúde, que trata de pesquisas com seres humanos (BRASIL, 2012). Sendo esta aprovada pelo Comitê de Ética em Pesquisa do Centro Universitário Doutor Leão Sampaio - UNILEÃO, com o parecer consubstanciado: 2.789.097, e CAAE: 91526418.8.0000.5048.

\section{RESULTADOS}

A pesquisa contou com 2.006 oportunidades de Higienização das Mãos (HM), sendo estas divididas entre $10,47 \%(n=210)$ para enfermeiros, e 89,53\% $(n=1.796)$ para técnicos de enfermagem.

As observações foram realizadas em três instituições hospitalares (pública, filantrópica e privada), as quais foram distribuídas do seguinte modo: 38,48\% ( $n=772$ ) observações realizadas na instituição pública, 33,15\% ( $n=665)$ na filantrópica, e 28,37\% ( $n=569)$ na instituição privada.

Evidenciou-se que $77,2 \%(n=1.548)$ dos profissionais de enfermagem aderiram à HM. Quando observado por subcategoria profissional, a adesão à $\mathrm{HM}$ foi de $83,8 \%(n=176)$ dos enfermeiros e $76,4 \%(n=1.372)$ dos técnicos de enfermagem (Tabela 1).

Tabela 1 - Adesão às práticas de higienização das mãos pelos profissionais de enfermagem no Cariri Cearense. Juazeiro do Norte, Ceará, Brasil. 2019.

\begin{tabular}{|c|c|c|c|c|c|c|}
\hline \multirow{3}{*}{ Ação } & \multicolumn{4}{|c|}{ Categoria Profissional } & & \\
\hline & \multicolumn{2}{|c|}{ Enfermeiro(a) } & \multicolumn{2}{|c|}{$\begin{array}{l}\text { Técnico(a) de } \\
\text { enfermagem }\end{array}$} & \multicolumn{2}{|c|}{ Geral } \\
\hline & $\mathbf{n}$ & $\%$ & $\mathbf{n}$ & $\%$ & $\mathbf{n}$ & $\%$ \\
\hline Higienizou & 176 & 83,8 & 1372 & 76,4 & 1548 & 77,2 \\
\hline Álcool & 10 & 4,8 & 55 & 3,1 & 65 & 3,2 \\
\hline Sabonete & 166 & 79,0 & 1317 & 73,3 & 1483 & 73,9 \\
\hline Não higienizou & 34 & 16,2 & 424 & 23,6 & 458 & 22,8 \\
\hline Não usou nada & 30 & 14,3 & 352 & 19,6 & 382 & 19,0 \\
\hline Luvas & 4 & 1,9 & 72 & 4,0 & 76 & 3,8 \\
\hline
\end{tabular}

Fonte: Coelho HP, et al., 2019.

Os dados referentes à ação advinda da indicação, mostram que, para os enfermeiros, é predominante o uso do sabonete $(79 \%, n=166)$, seguido do ato de não $\mathrm{HM}(14,3 \%, n=30)$. Já para os técnicos de enfermagem, também foi observado o uso do sabonete $(73,3 \%, n=1.317)$, seguido da não HM (19,6\%, $n=382)$. 
Um resultado positivo é que frente as indicações direcionadas aos profissionais de enfermagem, somente um pequeno percentual das oportunidades teve como resultado o uso da luva de procedimentos em substituição a $\mathrm{HM}(1,9 \%, n=4$ das ações realizadas pelos enfermeiros e 4,0\%, $n=72$ pelos técnicos de enfermagem).

Uma adesão mínima ocorreu também na adoção da fricção antisséptica das mãos com solução alcóolica (4,8\%, $n=10$ dos enfermeiros e $3,1 \%, n=55$ dos técnicos de enfermagem).

Para os enfermeiros, de acordo com o número de oportunidades por indicação, observou-se um índice expressivo de HM na recomendação Antes de Tocar o Paciente, sendo este composto por $(95,2 \%, n=40)$ das ações realizadas pelos enfermeiros, seguido da indicação Após Risco de Exposição a Fluidos Corporais $(89,5 \%, n=34)$. Ao passo que a menor adesão foi observada na indicação Após Tocar Superfícies Próximas ao Paciente $(74,1 \%, n=20)$ (Tabela 2).

Para os técnicos de enfermagem, evidenciou-se uma maior adesão na indicação Após Risco de Exposição a Fluidos Corporais $(84,6 \%, n=192)$, sendo que, similar aos enfermeiros, a menor adesão foi evidenciada na indicação Após Tocar Superfícies Próximas ao Paciente, (45,3\%, n=105) (Tabela 2).

Tabela 2 - Adesão da equipe de enfermagem por indicação à higienização das mãos nos cinco momentos preconizados pela OMS, em UTIN da região do Cariri Cearense. Juazeiro do Norte, Ceará, Brasil. 2019.

\begin{tabular}{|c|c|c|c|c|c|c|c|}
\hline \multirow{3}{*}{ Indicação para ação } & \multirow{3}{*}{ Ação } & \multicolumn{6}{|c|}{ Categoria Profissional } \\
\hline & & \multicolumn{2}{|c|}{ Enfermeiro(a) } & \multicolumn{2}{|c|}{$\begin{array}{l}\text { Técnico(a) de } \\
\text { enfermagem }\end{array}$} & \multicolumn{2}{|c|}{ Geral } \\
\hline & & $\mathbf{n}$ & $\%$ & $\mathbf{n}$ & $\%$ & $\mathbf{N}$ & $\%$ \\
\hline \multirow{3}{*}{ Antes de tocar o paciente } & Higienizou & 40 & 95,2 & 299 & 80,4 & 339 & 81,9 \\
\hline & Não higienizou & 2 & 4,8 & 73 & 19,6 & 75 & 18,1 \\
\hline & & 42 & 100,0 & 372 & 100,0 & 414 & 100,0 \\
\hline \multirow{3}{*}{$\begin{array}{c}\text { Antes de realizar } \\
\text { procedimento } \\
\text { limpo/asséptico }\end{array}$} & Higienizou & 35 & 81,4 & 209 & 73,6 & 244 & 74,6 \\
\hline & Não higienizou & 8 & 18,6 & 75 & 26,4 & 83 & 25,4 \\
\hline & & 43 & 100,0 & 284 & 100,0 & 327 & 100,0 \\
\hline \multirow{3}{*}{$\begin{array}{l}\text { Após risco de exposição } \\
\text { a fluidos corporais }\end{array}$} & Higienizou & 34 & 89,5 & 192 & 84,6 & 226 & 85,3 \\
\hline & Não higienizou & 4 & 10,5 & 35 & 15,4 & 39 & 14,7 \\
\hline & & 38 & 100,0 & 227 & 100,0 & 265 & 100,0 \\
\hline \multirow[t]{3}{*}{ Após tocar o paciente } & Higienizou & 47 & 78,3 & 567 & 83,3 & 614 & 82,9 \\
\hline & Não higienizou & 13 & 21,7 & 114 & 16,7 & 127 & 17,1 \\
\hline & & 60 & 100,0 & 681 & 100,0 & 741 & 100,0 \\
\hline \multirow{3}{*}{$\begin{array}{l}\text { Após tocar superfícies } \\
\text { próximas ao paciente }\end{array}$} & Higienizou & 20 & 74,1 & 105 & 45,3 & 125 & 48,3 \\
\hline & Não higienizou & 7 & 25,9 & 127 & 54,7 & 134 & 51,7 \\
\hline & & 27 & 100,0 & 232 & 100,0 & 259 & 100,0 \\
\hline
\end{tabular}

Fonte: Coelho HP, et al., 2019.

\section{DISCUSSÃO}

A grande quantidade de oportunidades direcionadas aos técnicos de enfermagem $(n=1.796)$, em relação aos enfermeiros $(n=210)$, pode ser justificada pela metodologia adotada no estudo e pela Portaria $n=895$, de 31 de março de 2017. A Portaria elucida as premissas do dimensionamento do pessoal de enfermagem na UTIN, descrevendo no quadro de pessoal a necessidade da atuação de pelo menos um enfermeiro plantonista, para cada dez leitos, em cada turno, e um técnico de enfermagem para cada dois leitos (BRASIL, 2017).

Como método de avaliação da qualidade da assistência dos serviços de saúde pode-se empregar o Índice de Positividade de Carter (IPC), o qual pode ser compreendido do seguinte modo: $100 \%$ de adesão caracteriza uma assistência desejada; de 90 a 99\% uma assistência adequada; de 80 a $89 \%$ uma assistência 
segura; de 70 a $79 \%$ uma assistência limítrofe; e menor que $70 \%$ uma assistência indesejada ou sofrível (LLAPA-RODRÍGUEZ EO, et al., 2018).

Estudos contemporâneos realizados nos estados de Sergipe, Minas Gerais, Paraná e Rio Grande do Sul, acerca da adesão à HM pela equipe de saúde, atuante nos setores de oncologia adulta e pediátrica, Unidade de Terapia Intensiva Adulto (UTI-a), pronto-socorro, e ambulatório geral, apontam para uma adesão global dos profissionais de enfermagem de, respectivamente, $34 \%, 47,8 \%, 54,2 \%$ e 25,76 , o que classifica a assistência, nestes casos, como indesejável ou sofrível (menor que 70\%), de acordo com o IPC (LLAPARODRÍGUEZ EO, et al., 2018; VASCONCELOS RO, et al., 2018; ZOTTELE C, et al., 2017; SOUZA LM, et al., 2015).

Resultado este divergente do encontrado neste estudo, o qual evidenciou adesão global a HM de $77,2 \%$, o que caracteriza a assistência limítrofe, conforme o referido índice. Outro estudo encontrou a adesão superior ao evidenciado nesta pesquisa, 82,4\%, o que significa assistência segura (MOTA EC, et al., 2014). Ao considerar apenas enfermeiros, a adesão foi de $83,3 \%$. Já para os técnicos foi de $76,4 \%$, classificando como assistência segura e limítrofe, respectivamente, de acordo com o IPC. Resultado este satisfatório, em comparação com estudos recentes (LLAPA-RODRíGUEZ EO, et al., 2018; VASCONCELOS RO, et al., 2018; ZOTTELE C, et al., 2017; SOUZA LM, et al., 2015).

A assistência realizada pelos técnicos de enfermagem está classificada como limítrofe, observando-se a necessidade da adoção de medidas de educação continuada, por parte das instituições de saúde e, também, a melhoria na oferta de insumos. Estas medidas podem favorecer a maximização da adesão dos profissionais à $\mathrm{HM}$, visto que são estes que, em detrimento das suas características laborais, atuam em maior contato com os pacientes.

Em alusão a adesão apresentada pelos enfermeiros e técnicos de enfermagem, evidenciou-se similaridade diante das ações, advindas das indicações, nas quais foi evidenciado o predomínio do uso do sabonete, e do ato de não HM.

Estudo realizado na UTI de um hospital de referência no atendimento ao trauma e queimaduras, no município de Porto Alegre, observou adesão à HM com sabonete pelos enfermeiros de $34,5 \%$, e dos técnicos de enfermagem de $21 \%$ (SOUZA LM, et al., 2015). Resultado este que diverge dos dados averiguados nesta análise, mostrando percentuais superiores, nos quais foram evidenciados a adesão à HM com sabonete em $79 \%$ das oportunidades despendidas aos enfermeiros e $73,3 \%$ dos técnicos de enfermagem.

Foi evidenciado em outro estudo percentual de $52,5 \%$ de não adesão às práticas de $\mathrm{HM}$ nas oportunidades despendidas aos enfermeiros, e $70,2 \%$ aos técnicos de enfermagem (SOUZA LM, et al., 2015). Resultado este preocupante, quando comparado à taxa de não adesão encontrada neste estudo, 16,2\% para enfermeiros e $23,6 \%$ para técnicos de enfermagem.

Diversos estudos contemporâneos associam a baixa adesão à HM não apenas a carência de conhecimentos teóricos dos profissionais, mas sim ao emprego destes em seu cotidiano. Somado ainda, por vezes, à falta de motivação para que os profissionais realizem a $\mathrm{HM}$, a não concepção do risco de transmissão cruzada de microrganismos, e/ou a deficiência da infraestrutura da instituição hospitalar, das quais pode-se citar a necessidade de dispensadores de álcool a 70\% devidamente instalados e abastecidos em cada leito e/ou setor (LLAPA-RODRÍGUEZ EO, et al., 2018; RAIMONDI DC, et al., 2017).

Observando-se as consequências da não higienização das mãos, há de se considerar que é possível correlacionar o surto de transmissão bacteriana com déficits de higienização das mãos, entre outras causas (ABERG E, et al., 2019).

Quanto à utilização de luvas em substituição à $\mathrm{HM}$, o resultado encontrado $(3,8 \%, \mathrm{n}=76)$ apesar de ser o menor percentual, está em desacordo com o preconizado pela Agência Nacional de Vigilância Sanitária (ANVISA). Esta afirma que a utilização das luvas não modifica nem substitui a prática da HM. Ressalta-se que as luvas não devem ser utilizadas indiscriminadamente pelos profissionais da saúde, sendo indicada somente nas situações preconizadas (BRASIL, 2016). 
Quanto à adoção de solução alcoólica, houve adesão mínima $(3,2 \%, n=65)$. Um estudo realizado em hospital escola de São Paulo, em meio a 1.206 oportunidades de HM, não houve nenhuma adesão à fricção alcoólica (SANTOS TCR, et al., 2014).

No entanto, estudo realizado em hospital universitário de Minas Gerais evidenciou adesão dos profissionais de enfermagem de $31 \%$ à HM com antissépticos alcoólicos (OLIVEIRA AC e GAMA CS, 2016).

O Protocolo para a Prática de Higiene das Mãos em Serviços de Saúde preconiza que a HM com preparação alcóolica pode ser utilizada como substituta a HM com sabonete líquido, desde que as mãos não estejam visivelmente sujas, visto que a fricção alcóolica não remove sujidades (BRASIL, 2017).

Estudo realizado sobre a avaliação da atividade antimicrobiana persistente de antissépticos à base de álcool contra contaminação bacteriana das mãos, evidenciou que as soluções alcoólicas são mais eficazes no controle microbiológico do que somente a higienização simples das mãos com água e sabão, devido ao seu efeito persistente contra contaminação (LÓPEZ-GIGOSOS RM, et al., 2017). Diante do exposto, a baixa adesão dos profissionais à fricção com solução alcóolica pode ser justificada pelo quantitativo reduzido dos dispensadores de álcool presentes em duas, das três UTIN das instituições pesquisadas.

Assim, sob a perspectiva de promover maior adesão dos profissionais de enfermagem à HM na UTIN, cabe aos enfermeiros, por serem responsáveis pela supervisão da equipe de enfermagem, e as instituições hospitalares promoverem medidas facilitadoras da adesão da equipe de enfermagem à prática de HM. É possível citar: promover sessões educativas para os profissionais da saúde quanto aos riscos e implicações da transmissão cruzada, assim como higienização correta das mãos; prover insumos e materiais de boa qualidade; realizar campanhas sobre higienização das mãos (OLIVEIRA AC e GAMA CS, 2016).

Quanto a adesão dos enfermeiros a indicação para a HM, houve maior adesão aos momentos: Antes de Tocar o Paciente (95,2\%, n=40) e a indicação Após Risco de Exposição a Fluídos Corporais (89,5,3\%, n=34). Quando comparados aos dados referentes aos técnicos de enfermagem, estas posições se invertem (Após Risco de Exposição a Fluídos Corporais 84,6\%, n=192; Antes de Tocar o Paciente 80,4\%, $n=299$ ).

Diante da adesão dos profissionais de enfermagem a ação advinda da indicação de HM, um resultado preocupante é que a menor taxa de adesão foi evidenciada na indicação Após Tocar Superfícies Próximas ao Paciente (enfermeiros $74,1 \%, n=20$, técnicos de enfermagem $45,3 \%, n=105$ ). Porém, o resultado é semelhante ao evidenciado em estudo realizado em UTI-a do município de Curitiba, no qual a indicação Após Tocar Superfícies Próximas ao Paciente representou a maior taxa de adesão entre a equipe de enfermagem, 42,3\% (VASCONCELOS RO, et al., 2018).

Os cinco momentos preconizados pela OMS para HM podem ser organizados em duas subclasses. É possível averiguar que as duas primeiras indicações (Antes de Tocar o Paciente, Antes de Realizar Procedimento Limpo/Asséptico) relacionam-se ao cuidado e proteção do paciente contra as IRAS. Já as três últimas indicações (Após o Risco de Exposição a Fluídos Corporais, Após Tocar o Paciente e Após Tocar Superfícies Próximas ao Paciente) estão relacionadas ao autocuidado dos profissionais com sua saúde e/ou com a prevenção de infecções cruzadas no ambiente de trabalho (CASTRO AF e RODRIGUES MCS, 2018).

Estudo realizado na UTI de hospital universitário acerca da adesão dos profissionais de enfermagem à HM nos cinco momentos preconizados pela OMS, aponta para maior adesão, pelos enfermeiros, na indicação Após Tocar o Paciente (100\%), seguido da indicação Após Tocar Superfícies Próximas ao Paciente (40\%). Resultado este divergente do apresentado neste estudo, na qual a maior adesão foi evidenciada na indicação Antes de Tocar o Paciente (95,2\%). Isto correlaciona-se com a possível compreensão dos profissionais quanto aos riscos de infecção aos quais os pacientes estão expostos, diante da não adesão à HM nas duas primeiras indicações (VASCONCELOS RO, et al., 2018).

Diante da adesão dos técnicos de enfermagem às indicações de HM, estudo acerca da adesão da equipe de enfermagem à HM em UTI-ped, evidenciou adesão de 64,7\% à indicação Após Risco de Exposição a Fluídos Corporais, seguido da indicação Antes de Realizar Procedimento Limpo/Asséptico (60\%) (RAIMONDI DC, et al., 2017). Resultado este que caminha de encontro ao evidenciado neste estudo, no qual, diante da 
avaliação dos técnicos de enfermagem, também foi averiguada maior adesão na indicação Após Risco de Exposição a Fluídos Corporais $(84,6 \%, n=192)$.

Em suma, neste estudo, os enfermeiros apresentaram maior adesão à indicação Antes de Tocar 0 Paciente, o que evidencia sua preocupação com a exposição do cliente a riscos, tais como infecções cruzadas. Ao passo que para os técnicos de enfermagem, a maior adesão foi observada na indicação Após Risco de Exposição a Fluídos Corporais, o que pode estar relacionado a uma carência de conhecimentos específicos por estes profissionais, quanto aos riscos advindos da não higienização das mãos nas indicações antes do contato com o paciente, tais como a exposição dos pacientes as IRAS.

Resultado este que sugere que os técnicos de enfermagem tiveram maior comprometimento com sua própria segurança, evidenciado pela maior adesão à higienização das mãos Após Risco de Exposição a Fluídos Corporais. Este dado pode estar relacionado ao risco de adquirir doenças após a realização de procedimentos, pela exposição a fluídos corporais e/ou pelo contato com áreas potencialmente contaminadas do paciente (ZOTTELE C, et al., 2017).

Diante do resultado, evidencia-se, principalmente, não observância dos profissionais de enfermagem à higienização das mãos na indicação Após Tocar Superfícies Próximas ao Paciente. Aspecto este, que remete a carência de informações destes profissionais, e medidas de educação continuada, por parte da instituição hospitalar, dos demais profissionais da área da saúde e da Comissão de Prevenção de Infecção Hospitalar, quanto à importância da assistência segura ao paciente.

Como fragilidade do método utilizado, mesmo com todas as medidas utilizadas para redução desta, inferese que o Efeito Hawthorne pode ter influenciado na adesão apresentada pelos profissionais de enfermagem, visto que o mesmo se refere à mudança de comportamento dos participantes quando observados (OLIVEIRA AC, et al., 2016).

\section{CONCLUSÃO}

Quando comparados os comportamentos dos enfermeiros e técnicos de enfermagem, avaliou-se que a maioria aderiu a higienização das mãos, classificando-se a assistência como segura para os enfermeiros e limítrofe para os técnicos de enfermagem. Evidenciou-se, também, maior adesão da equipe de enfermagem à higienização simples das mãos com água e sabão, seguido da não higienização das mãos. Assim, apesar das taxas de adesão encontradas neste estudo serem satisfatórias, é necessário que as instituições de saúde promovam medidas que favoreçam a capacitação contínua dos profissionais de enfermagem, frente à prevenção das IRAS, visando, a partir destas, a conscientização da equipe de saúde para a preservação da sua integridade física, e a oferta de assistência cada vez mais qualificada, resolutiva e segura aos pacientes.

\section{REFERÊNCIAS}

1. LLAPA-RODRÍGUEZ EO, et al. Aderência de profissionais de saúde à higienização das mãos. Rev enferm UFPE on line, 2018; 12(6):1578-85.

2. FELDHAUS C, et al. Conhecimento de acadêmicos de enfermagem e fisioterapia sobre higiene das mãos. Rev Min Enferm, 2018; 22:e-1096.

3. MOTA EC, et al. Higienização das Mãos: uma avaliação da adesão e da prática dos profissionais de saúde no controle das infecções hospitalares. Rev Epidemiol Control Infect, 2014; 4(1):12-7.

4. DERHUN FM, et al. Conhecimento de profissionais de enfermagem sobre higienização das mãos. Cogitare Enferm, 2016; 21(3): 1-8.

5. RAIMONDI DC, et al. Higienização das mãos: adesão da equipe de enfermagem de unidades de terapia intensiva pediátricas. Rev Cuid, 2017; 8(3): 1839-48.

6. BRASIL. Ministério da Saúde. Assistência Segura: uma reflexão teórica aplicada à prática. Brasília: Ministério da Saúde; 2013. Disponível em: http://portal.anvisa.gov.br/documents/33852/3507912/Caderno+1++ Assist\%C3\%AAncia+Segura+-

+Uma+Reflex\%C3\%A30+Te\%C3\%B3rica+Aplicada+\%C3\%A0+Pr\%C3\%A1tica/97881798-cea0-4974-9d9b-

077528ea1573. Acesso em: 22 de maio de 2019. 
7. BRASIL. Ministério da Saúde. Boletim Segurança do Paciente e Qualidade em Serviços de Saúde no 16: avaliação dos indicadores nacionais das Infecções Relacionadas à Assistência à Saúde (IRAS) e Resistência microbiana do ano de 2016. Brasília: Ministério da Saúde; 2017. Disponível em: https://www20.anvisa.gov.br/segurancadopaciente/index.php/publicacoes/item/boletim-seguranca-do-paciente-equalidade-em-servicos-de-saude-n-16-avaliacao-dos-indicadores-nacionais-das-infeccoes-relacionadas-aassistencia-a-saude-iras-e-resistencia-microbiana-do-ano-de-2016. Acesso em: 21 de agosto de 2018.

8. PIMENTEL CS, et al. Infecção relacionada à assistência a saúde em unidade de terapia intensiva. Rev Enferm UFPI, 2018; 7(3):61-6.

9. BRASIL. Ministério da Saúde. Assistência Segura: uma reflexão teórica aplicada à prática. Brasília: Ministério da Saúde; 2017. Disponível em: http://portal.anvisa.gov.br/documents/33852/3507912/Caderno+1++ Assist\%C3\%AAncia+Segura+-

+Uma+Reflex\%C3\%A3o+Te\%C3\%B3rica+Aplicada+\%C3\%A0+Pr\%C3\%A1tica/97881798-cea0-4974-9d9b077528ea1573. Acesso em: 31 de julho de 2019.

10. VASCONCELOS RO, et al. Adesão à higienização das mãos pela equipe de enfermagem em unidade de terapia intensiva. Enfermería global, 2018; 50:446-61.

11. BRASIL. Ministério da Saúde. Manual de Referência Técnica para a Higiene das Mãos. Brasília: Ministério da Saúde; 2009. Disponível em: https://www20.anvisa.gov.br/segurancadopaciente/index.php/publicacoes?task=callelement\&format=raw\&item_id=4 25\&element $=f 85 c 494 b-2 b 32-4109-b 8 c 1-$

083cca2b7db6\&method=download\&args[0]=ce7e5ccb40e60fc2a86085e5c8244fa1. Acesso em: 28 de julho de 2019.

12. ABRAHAM MB, at al. The importance of the hawthorne effect on psychological outcomes unveiled in a randomized controlled trial of diabetes technology. J Diabetes Sci Technol, 2018; 12(3):735-6.

13. BRASIL. Resolução $n^{\circ} 466 / 2012$. Aprova as diretrizes e normas regulamentadoras de pesquisas envolvendo seres humanos. Brasília: 2013. Disponível em: http://bvsms.saude.gov.br/bvs/saudelegis/cns/2013/res0466_12_12_2012.html. Acesso em: 27 de março de 2019.

14. BRASIL. Ministério da Saúde. Portaria MS/GM n- 895/2017. Institui o cuidado progressivo ao paciente crítico ou grave com os critérios de elegibilidade para admissão e alta, de classificação e de habilitação de leitos de Terapia Intensiva Adulto, Pediátrico, Unidade Coronariana, Queimados e Cuidados Intermediários Adulto e Pediátrico no âmbito do Sistema Único de Saúde (SUS). Brasília: Ministério da Saúde; 2017. Disponível em: http://www.in.gov.br/materia//asset_publisher/Kujrw0TZC2Mb/content/id/20139423/do1-2017-04-03-portaria-n-895-de-31-de-marco-de-201720139271. Acesso em: 25 de julho de 2019.

15. ZOTTELE C, et al. Hand hygiene compliance of healthcare professionals in an emergency department. Rev Esc Enferm USP, 2017; 51: e03242.

16. SOUZA LM, et al. Adesão dos profissionais de terapia intensiva aos cinco momentos da higienização das mãos. Rev Gaúcha Enferm 2015; 36(4):21-8.

17. ABERG E, et al. Harbouring group $B$ streptococci in a neonatal intensive care unit led to an outbreak among preterm infants. Foundation Acta Paediatrica 2019; 108:58-61.

18. BRASIL. Secretaria de Estado da Saúde. Centro de Vigilância Epidemiológica. Divisão de Infecção Hospitalar. Recomendações sobre o Uso de Luvas em Serviços de Saúde. 2016. Disponível em: http://www.saude.sp.gov.br/resources/cve-centro-de-vigilancia-epidemiologica/areas-de-vigilancia/infeccaohospitalar/bmr/doc/ih16_bmr_uso_luvas.pdf. Acesso em: 31 de julho de 2019.

19. SANTOS TCR, et al. Higienização das mãos em ambiente hospitalar: uso de indicadores de conformidade. Rev Gaúcha Enferm, 2014; 35(1):70-7.

20. OLIVEIRA AC, GAMA CS. Antissepsia cirúrgica e utilização de luvas cirúrgicas como potenciais fatores de risco para contaminação transoperatória. Esc. Anna Nery, 2016; 20(2):370-7.

21. LÓPEZ-GIGOSOS RM, et al. Evaluation of antimicrobial persistent activity of alcohol-based hand antiseptics against bacterial contamination. Eur J Clin Microbiol Infect Dis, 2017; 36(7):1197-203.

22. CASTRO AF, RODRIGUES MCS. Infraestrutura e indicadores de adesão à higiene das mãos em unidade de terapia intensiva. Rev baiana enferm, 2018; 32:e26099.

23. OLIVEIRA AC, et al. Adesão à higienização das mãos entre técnicos de enfermagem em um hospital universitário. Rev enferm UERJ, 2016; 24(2):e9945. 